\title{
JOURNAL.RU
}

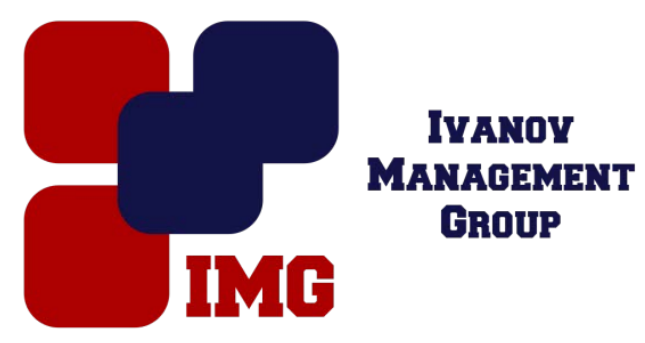

Меладзе Р.Д., Томарева Е.И., Геймерлинг В.Э.

Тульский государственный университет

Тула, Россия

doi: 10.18411/lj-31-03-2017-2-12

idsp 000001:lj-31-03-2017-2-12

\section{Корреляционный анализ риска развития наиболее частых хромосомных синдромов у человека}

Одним из ведущих путей ранней диагностики хромосомной патологии с последующей элиминацией пораженных плодов является пренатальная диагностика, в процессе которой формируется группа беременных с высоким риском патологических состояний плода. Женщинам, при наличии у плода риска детектируемых хромосомных синдромов, превышающего 1:100, предлагается пройти инвазивную пренатальную диагностику и принять решение по результату обследования [1-2].

Целью исследования послужило изучение взаимосвязей различных признаков с величиной риска развития некоторых хромосомных синдромов.

Объектом исследования послужили 78 беременных женщин Тульской области, обследовавшиеся в МГЦ ТОПЦ в 2013-2014 году. Корреляционный анализ произведен по данным, полученным методом выкопировки из медицинской документации и проспективного анкетирования женщин [3].

Риск возникновения наиболее частых трисомий (синдрома Дауна, Патау, Эдвардса) сходным образом увеличивался в зависимости от возраста женщины $(\mathrm{r}=0,606 ; 0,635 ; 0,537$ соответственно, $\mathrm{p}<0,001)$, наличия гипоплазии или отсутствия костной части носа плода $(\mathrm{r}=0,541 ; 0,581 ; 0,527$ соответственно, $\mathrm{p}<0,001)$, толщины воротникового пространства ( $\mathrm{r}=0,366, \mathrm{p}=0,002 ; 0,362$, $\mathrm{p}=0,002 ; 0,323, \mathrm{p}=0,006$ соответственно). Установлены средняя положительная корреляционная взаимосвязь между паритетом текущих родов и риском возникновения с. Дауна $(\mathrm{r}=0,380, \mathrm{p}=0,001)$ и с. Патау $(\mathrm{r}=0,337, \mathrm{p}=0,004)$. Кандидоз влагалища состоял в слабой положительной корреляционной 
взаимосвязи с риском с. Дауна $(\mathrm{r}=0,232, \mathrm{p}=0,050)$ и с. Эдвардса $(\mathrm{r}=0,241$, $\mathrm{p}=0,041)$, тогда как у женщин при наличии уреаплазмоза и простудных заболеваний в анамнезе отмечалась отрицательная взаимосвязь с риском развития с. Эдвардса ( $\mathrm{r}=-0,265, \mathrm{p}=0,024$ и $\mathrm{r}=-0,275, \mathrm{p}=0,019$ соответственно). Также выявлена слабая отрицательная корреляционная взаимосвязь риска с. Эдвардса с абсолютным и относительным содержанием b-HCG (r=-0,251, $\mathrm{p}=0,033$ и $\mathrm{r}=-0,298, \mathrm{p}=0,011$ соответственно).

Из факторов образа жизни беременных женщин, увеличивающих риск хромосомных синдромов, выделяются высокий уровень умственного напряжения трудовой деятельности при с. Дауна $(\mathrm{r}=0,289, \mathrm{p}=0,023)$ и несоблюдение режима питания для с. Патау $(\mathrm{r}=0,260, \mathrm{p}=0,028)$ и с. Эдвардса $(\mathrm{r}=0,234, \mathrm{p}=0,047)$. Вместе с тем подтверждена сильная корреляционная взаимосвязь между изучаемыми хромосомными синдромами (r=0,808-0,950, $\mathrm{p}<0,001)$.

Таким образом, в настоящем исследовании подтверждены ранее известные предрасполагающие хромосомной патологии признаки (возраст женщины, визуализация носовой кости и толщины воротникового пространства плода) и установлены новые достоверные кандидатные признаки, которые в перспективе могут быть использованы для уточнения расчетов по предполагаемым хромосомным синдромам плода.

\section{Литература}

1. Павлов О.Г., Кононенко Н.И., Тюрина Г.Л., Мандрик И.А., Тетерина С.П., Кононова М.В., Ржевкина Н.Н. Инвазивная пренатальная диагностика в практике Курской областной медико-генетической консультации // Медицинская генетика. 2005. Т. 4. № 5. C. 245.

2. Павлов О.Г. Прикладные вопросы ситуационного управления в социальномедицинской сфере. Старый Оскол: ТНТ, 2009. 276 с.

3. Овчинкин О.В., Овчинкина Т.В., Павлов О.Г. Персональное моделирование заболеваний сердечно-сосудистой системы с применением нейронных сетей и инструментальных средств. Вестник новых медицинских технологий. 2011. Т. 18. № 4. C. 41-43. 